\title{
Rapid and Efficient Preparation of Free Amino Acids from Strong Acid Salts on Columns of Crosslinked Poly-4-vinylpyridine
}

\author{
DOUglas M. JEWETT ${ }^{1}$ AND Richard L. EHRENKAUfER \\ Department of Internal Medicine, Division of Nuclear Medicine, University of Michigan, \\ Ann Arbor, Michigan 48109
}

Received November 11, 1981

\begin{abstract}
Acidic and neutral amino acids were recovered from their strong acid salts or from large excesses of strong acids by passage through columns of crosslinked poly-4-vinylpyridine. Basic amino acids eluted as the monoacid salts. High recoveries were possible with submicromolar samples.
\end{abstract}

Frequently, procedures for synthesizing or deblocking amino acids employ strong acids, which must usually be removed for subsequent steps. Blomquist et al. (1) discussed shortcomings in available methods and developed a new procedure for recovery of amino acids from their hydrohalide salts by neutralization with triethylamine and crystallization of the free amino acids. Recoveries were in the range of $72-98 \%$. Methods involving crystallization are usually unsatisfactory for analytical samples, which involve small quantities, mixtures, and compounds of unknown solubility. A recent method avoids the need for recrystallization by converting hydrochloride salts to free amino acids by formation and subsequent solvolysis of trimethylsilyl derivatives $(2,3)$. Procedures using ethylene oxide or propylene oxide have also been reported recently. $(4,5)$.

We have obtained amino acids, in most cases in greater than $99 \%$ yield, by simply passing aqueous solutions of strong acid salts

\footnotetext{
${ }^{1}$ To whom correspondence should be addressed at: Nuclear Medicine, Box 021, University Hospital, Ann Arbor, Mich. 48109.
}

of the amino acids through columns of crosslinked poly-4-vinylpyridine. Recrystallization is unnecessary provided that a trace of contamination by the salt can be tolerated in the product (Table 1). The method works not only for hydrohalide salts but for all strong acid salts tested (Table 2). Further, a small amount of amino acid may be recovered from a large excess of strong acid solution. For efficient removal of the strong acid more than 1 eq of the resin was required (Table 3). For the hydrophobic amino acids the column and outlet line were maintained at $98^{\circ} \mathrm{C}$ in a water bath to avoid premature crystallization of the product. Basic amino acids and glycine ethyl ester eluted mainly as the monoacid salts instead of the desired free bases (Table 1). However, it was possible to recover ornithine and histidine as the trifluoroacetate salts in submicromolar amounts from 1000- and 10,000-fold excess, respectively, of trifluoroacetic acid (Table 4). While we have applied the above procedure to the amino acids because they offer a case of special difficulty and wide applicability, clearly the method should be useful for the recovery of many kinds of water-soluble molecules from strong acids. 
TABLE 1

Conversion of Amino Acid Salts to Free Amino Acids by Crosslinked Polyvinylpyridine ${ }^{a}$

\begin{tabular}{|c|c|c|c|}
\hline Amino acid salt ${ }^{b}$ & $\begin{array}{l}\text { Free amino } \\
\text { acid expected } \\
\quad(\mathrm{mg})\end{array}$ & $\begin{array}{l}\text { Product } \\
\text { (mg) }\end{array}$ & $\begin{array}{l}\text { Acid salt in } \\
\text { product }^{\mathrm{c}} \\
(\mathrm{mmol})\end{array}$ \\
\hline L-Leucine-HCl ${ }^{d}$ & 131.2 & 131.0 & e \\
\hline L-Valine-HBr $\mathbf{r}^{d}$ & 117.2 & 116.5 & e \\
\hline L-Phenylalanine-HI ${ }^{d}$ & 165.2 & 165.8 & e \\
\hline L-Alanine- $1 / 2 \mathrm{H}_{2} \mathrm{SO}_{4}{ }^{f}$ & 89.1 & 89.8 & e \\
\hline L-Tyrosine- $\mathrm{HCl}^{d}$ & 90.6 & 89.4 & e \\
\hline L-Tryptophan-HBr ${ }^{d}$ & 204.2 & $185.5^{\mathrm{g}}$ & e \\
\hline L-Threonine-HCl ${ }^{f}$ & 119.1 & 119.8 & e \\
\hline L-Glutamic acid-HCl${ }^{d}$ & 147.1 & 147.9 & $\cdot$ \\
\hline L-Methionine-HI ${ }^{d}$ & 149.2 & 151.4 & e \\
\hline L-Cysteine-HBr ${ }^{f}$ & 121.2 & 120.5 & 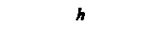 \\
\hline L-Proline- $\mathrm{HCl}^{f}$ & 115.1 & 116.7 & 0.02 \\
\hline L-Lysine-HCl ${ }^{f}$ & 146.2 & $183.4^{i}$ & 1.00 \\
\hline $\mathrm{L}$-Histidine- $\mathrm{HCl}^{f}$ & 155.2 & $171.2^{j}$ & 0.74 \\
\hline L-Arginine- $\mathrm{HCl}^{f}$ & 174.2 & $210.1^{i}$ & 1.01 \\
\hline L-Ornithine- $\mathrm{HCl}^{f}$ & 132.2 & $168.2^{i}$ & 0.99 \\
\hline Glutathion- $-\mathbf{H C l}^{d}$ & 153.6 & 154.1 & $e$ \\
\hline Glycine ethyl ester- $\mathrm{HCl}^{d}$ & 103.1 & h & 0.80 \\
\hline
\end{tabular}

a Poly-4-vinylpyridine, crosslinked, R-8050, available from Reilly Tar and Chemical Corp., 1510 Market Square Center, $151 \mathrm{~N}$. Delaware St., Indianapolis, Ind. 46204.

${ }^{b}$ One millimole of the salt was applied to a column containing 3.9 meq of the resin, except for tyrosine and glutathione $(0.5 \mathrm{mmol})$ where solubility was limited.

${ }^{c}$ Strong acid salts were determined gravimetrically as the $\mathrm{Ag}^{+}$(for $\mathrm{Cl}^{-}, \mathrm{Br}^{-}, \mathrm{I}^{-}, \mathrm{PO}_{4}^{2-}, \mathrm{Pb}^{2+}$ (for $\mathrm{F}^{-}$), or $\mathrm{Ba}^{2+}$ (for $\mathrm{SO}_{4}^{2-}$ ) salts.

'See text for procedure for hydrophobic amino acids.

- Trace, not weighable.

${ }^{f}$ See text for procedure for hydrophilic amino acids.

$\mathrm{g}$ Balance of material removed from column by subsequent wash.

" Not measured.

' Monohydrochloride salts.

${ }^{j}$ Mixture of monohydrochloride and free amino acid.

\section{PROCEDURES}

Typical procedure for hydrophobic amino acids; conversion of L-leucine hydrochloride to L-leucine. Four hundred milligrams ( 3.4 meq) of poly-4-vinylpyridine (R-8050, Reilly Tar and Chemical Corp.) was packed in a Pasteur pipet $(6 \times 30-\mathrm{mm}$ bed $)$ above a plug of glass wool. The column was saturated with water and allowed to equilibrate for a few hours. The pipet was then immersed in a boiling-water bath, and $6 \mathrm{ml}$ water was passed through the resin by gentle air pres- sure. The column was then placed in a 10$\mathrm{ml}$ flask with a neck long enough to surround the resin bed, and the flask was immersed to the top of the neck in boiling water. Leucine- $\mathrm{HCl}, 1 \mathrm{meq}(167.6 \mathrm{mg})$, dissolved in $4 \mathrm{ml}$ water was preheated in the bath and applied to the column, followed by two $1-\mathrm{ml}$ washes of hot water. Gentle nitrogen pressure was applied such that the flow rate was about $1 \mathrm{ml} / \mathrm{min}$. The column effluent was evaporated to dryness on a rotary evaporator and further dried for analysis in a vacuum over $\mathrm{P}_{2} \mathrm{O}_{5}$. The yield was $131.0 \mathrm{mg}(99.9 \%)$. 
TABLE 2

Removal of Strong Acids from AQueous SOLUTIONS BY A COLUMN OF POLYVINYLPYRIDINE ${ }^{a}$

\begin{tabular}{lcc}
\hline \multicolumn{1}{c}{ Acid } & $\begin{array}{c}\text { Acid applied } \\
\text { to column } \\
(\mathrm{mmol})\end{array}$ & $\begin{array}{c}\text { Acid } \\
\text { removed } \\
(\%)\end{array}$ \\
\hline $\mathrm{HCl}$ & 1.00 & $>99.9^{b}$ \\
$\mathrm{HBr}$ & 1.00 & $99.8^{b}$ \\
$\mathrm{HI}$ & 1.00 & $99.8^{b}$ \\
$\mathrm{HF}$ & 1.00 & $98.5^{b}$ \\
$\mathrm{H}{ }_{3} \mathrm{PO}_{4}$ & 0.33 & $98.9^{b}$ \\
$\mathrm{H}_{2} \mathrm{SO}_{4}$ & 0.50 & $>99^{c}$ \\
$\mathrm{~F}_{3} \mathrm{CCOOH}$ & 1.00 & $>99^{c}$ \\
$\mathrm{Cl}_{3} \mathrm{CCOOH}$ & 1.00 & $>99^{c}$ \\
\hline
\end{tabular}

${ }^{a}$ Resin, 3.8 meq.

${ }^{b}$ By gravimetric analysis, as in Table 1 .

'By titration.

Typical procedure for water-soluble amino acids; conversion of L-cysteine hydrobromide to L-cysteine. A column of poly4-vinylpyridine was packed, equilibrated, and washed as above. The subsequent steps were done at room temperature. Cysteine$\mathrm{HBr}, 1 \mathrm{mM}$ (202.1 mg), dissolved in $1 \mathrm{ml}$ water was applied to the column, followed

TABLE 3

Percentage of HCl Removed from $1 \mathrm{mmol}$ ALANINE-HydROCHLORIDE BY DIFFERENT AMOUNTS OF POLYVINYLPYRIDINE

\begin{tabular}{cc}
\hline Resin (meq) & $\mathrm{HCl}$ removed (\%) \\
\hline 1.0 & 87.0 \\
2.0 & 98.5 \\
3.0 & 98.9 \\
4.0 & 98.9 \\
\hline
\end{tabular}

TABLE 4

Sepakation of Basic amino acius from a Large EXCESS OF TRIFLUOROACETIC ACID

\begin{tabular}{lccc}
\hline Amino acid & $\begin{array}{c}\text { Amino } \\
\text { acid } \\
(\mu \mathrm{mol})\end{array}$ & $\begin{array}{c}\text { Column } \\
\text { conditions } \\
\text { and procedure }\end{array}$ & $\begin{array}{c}\text { Recovery } \\
(\%)\end{array}$ \\
\hline DL-Ornithine & 0.1 & $b$ & 96.6 \\
DL-Ornithine & 0.1 & $c$ & $>99.9$ \\
DL-Histidine & 0.01 & $b$ & 91.4 \\
DL-Histidine & 0.01 & $c$ & 97.5 \\
\hline
\end{tabular}

${ }^{a}$ Recovery determined by liquid scintillation count* ing.

${ }^{b}$ Specified amount of ${ }^{14} \mathrm{C}$-labeled amino acid in $1 \mathrm{ml}$ of $1 \mathrm{M}$ trifluoroacetic acid applied to column. Procedure followed for hydrophilic amino acid.

'Column preconditioned by exposure to $1 \mathrm{mmol}$ of the cold amino acid, followed by two $1-\mathrm{ml}$ rinses.

by two $1-\mathrm{ml}$ washes of water. The product was dried as above. The yield was 120.5 mg (99.4\%).

\section{ACKNOWLEDGMENTS}

This work was supported by Grant 5T32 CA09015 awarded by the National Cancer Institute, DHEW, by Grant 1 P01 N515655 awarded by NINCDS, DHEW, and by the Nuclear Medicine Research Fund. We thank Reilly Tar and Chemical Corporation for the sample of resin.

\section{REFERENCES}

1. Blomquist, A. T., Hiscock, B. F., and Harpp, D. N. (1973) Synth. Commun. 3, 343.

2. Rogozhin, S. V., Davidovich, Y. A., and Yurtanov, A. I. (1975) Synthesis 1975, 113.

3. Kricheldorf, H. R. (1975) Liebigs Ann. Chem. 1975, 1387.

4. Bey, P. (1979) J. Org. Chem. 44, 2732.

5. Constenla, M. (1978) Ign. Cienc. Quim. 1978, 11. 